\title{
OBITUARY
}

\section{DR. ANDREW WYLIE}

THE bright personality of Andrew Wylie will long be missed by those who were in the habit of meeting him in the hospital, the Society, the street, or on the golf course. Cheerful and methodical in his hospital duties, he was an exemplary colleague and one pre-eminently easy to work with. In the Royal Society of Medicine he was an attentive listener and a judicious critic, while his crisp and concise interpolations were all the more valued because they were always to the point, neither too long nor too frequent. It was always a pleasure to meet him socially and a privilege to sit at his hospitable board, over which he presided with his well-recognized geniality.

He studied medicine at the University of Glasgow and graduated M.B. and C.M. in I92I with honours in clinical surgery and pathology. After a period of general practice in Huddersfield he worked at Clinics in Paris and Vienna and decided to specialize in Laryngology. He came to London and was appointed to the Central London Throat, Nose and Ear Hospital.

At the Central London Throat and Ear Hospital his chivalrous devotion to the interests of the institution in general and of the humbler workers and patients in particular, gained for him the love and respect of the poor as well as of the well-to-do. His wisdom in counsel enabled him to obtain a ready hearing in the Committee of Management and his loss will also be felt in that sphere of usefulness.

His publications were not numerous, but were distinguished by their interest as well as their clinical value. Among the earliest was an investigation into the later history and fate of a large number of cases of malignant disease of the throat, and among the latter a paper on the diagnosis of cancer, syphilis and tuberculosis of the larynx. A study of one hundred cases of laryngeal growths showed his thoroughness. His Presidential address on "Rhinology and Laryngology in Literature and Folk-Lore", was a highly readable contribution with many references to writers of classical and literary distinction, some of whom are less well known than they should be.

His lamented death on January I2th was found to be due to atheroma of the coronary arteries and there is evidence that life must have been extinct before his fall into the stream from which his body was recovered.

James Dundas-Grant. 